\title{
Control of Graves' hyperthyroidism with very long-term methimazole treatment: a clinical trial
}

\author{
Fereidoun Azizi, Hengameh Abdi ${ }^{*}$ and Atieh Amouzegar ${ }^{*}$ [D
}

\begin{abstract}
Background: Long-term antithyroid drug therapy has become one of the options for treatment of Graves' hyperthyroidism. The aim of this study was to compare thyroid status in those who discontinued methimazole (MMI) treatment after 12.8 years with those who continued MMI as long as 24 years.
\end{abstract}

Methods: Fifty nine patients with Graves' disease on long-term MMI for $14.2 \pm 2.9$ years were recruited; 32 patients (54\%) decided to discontinue MMI and 27 (46\%) preferred additional years of MMI treatment. All patients were followed for a mean of 6 additional years.

Results: Of 27 patients who continued MMI up to 24 years, suppressed serum thyrotropin (TSH) was not observed in any patient after the seventh year of treatment. Serum free thyroxine, triiodothyronine, TSH and TSH receptor antibody concentrations remained normal up to the length of the study. Mean daily dose of MMI to maintain TSH in the reference range decreased gradually and reached to $2.8 \pm 1.7 \mathrm{mg}$ by 24 years of MMI treatment. No adverse reaction related to $\mathrm{MMI}$ occured during additional years of therapy. In 32 patients who discontinued MMI, hyperthyroidism relapsed in 6 patients (19\%), one left follow-up and 25 (78\%) remained euthyroid during the study.

Conclusions: Long-term low dose MMI treatment may be a lifelong effective and safe therapeutic modality in patients with Graves' hyperthyroidism for prevention of relapse, if studies from other centers confirm findings of this research.

Trial registration: IRCT201009224794N1, 2010-10-25. Retrospectively registered.

https://www.irct.ir/trial/5143.

\section{Introduction}

Antithyroid thionamide drugs (ATDs) have become the treatment of choice for Graves' disease (GD) in the United States, and majority of patients in other countries worldwide [1-3]. The major drawback of ATD therapy is its $20-70 \%$ recurrence rate of hyperthyroidism following discontinuation of the traditional 12-18 month treatment [4]. Serum thyrotropin (TSH) receptor antibody

\footnotetext{
*Correspondence: abdi@endocrine.ac.ir; hengamehabdi@gmail.com; amouzegar@endocrine.ac.ir; atiehamouzegar@yahoo.com

Endocrine Research Center, Research Institute for Endocrine Sciences, Shahid Beheshti University of Medical Sciences, P.O.Box: 19395-4763, 1985717413, No 24, Aerabi St, Daneshjoo Blv, Velenjak, Tehran, Iran
}

(TRAb) concentration, one major predictor of GD relapse, may fluctuate or remain positive in many patients with GD following ATD withdrawal and median time to remission may last as long as 6.8 years [5]. Hence, a few studies from different regions of the world have adopted the long-term continuous ATD therapy [6-10]; based on findings of a meta-analysis, remission rate increases by $16 \%$ for each additional year of ATD therapy after 24 months of ATD treatment [11]. These findings indicate that failure to attain normal TRAb concentrations after conventional 12-18 months of ATD treatment does not rule out the possibility of remission over a long-term ATD therapy [12]; therefore, long-term treatment of

C C The Author(s). 2021 Open Access This article is licensed under a Creative Commons Attribution 4.0 International License, which permits use, sharing, adaptation, distribution and reproduction in any medium or format, as long as you give appropriate credit to the original author(s) and the source, provide a link to the Creative Commons licence, and indicate if changes were made. The images or other third party material in this article are included in the article's Creative Commons licence, unless indicated otherwise in a credit line to the material. If material is not included in the article's Creative Commons licence and your intended use is not permitted by statutory regulation or exceeds the permitted use, you will need to obtain permission directly from the copyright holder. To view a copy of this licence, visit http://creativecommons.org/licenses/by/4.0/ The Creative Commons Public Domain Dedication waiver (http://creativecommons.org/publicdomain/zero/1.0/) applies to the data made available in this article, unless otherwise stated in a credit line to the data. 
Graves' hyperthyroidism has become an option in international societies recommendations [4, 13]. A recent randomized clinical trial reported that 5-year continuous methimazole (MMI) therapy is accompanied with $84 \%$ remission up to 4 years after drug withdrawal [14]. However, the optimal duration of ATD therapy is still debatable. Likewise, details of clinical and biochemical changes in those with ATD treatment > 10-15 years are scarce. In the present study, we aimed to compare thyroid status in patients who discontinued MMI treatment after 12.8 years with those who continued MMI therapy for as long as 24 years.

\section{Methods}

The study protocol was approved by the ethics committee of the Research Institute for Endocrine Sciences and all patients gave written informed consent.

This study is an extension of long-term methimazole (LT-MMI) treatment of patients with GD [7]. From March 1987, all patients with recurrent GD who had ongoing long-term methimazole (LT-MMI) therapy, as part of a clinical trial entitled "Towards Outstanding Hyperthyroid care Induced by anthithyroid Drugs" (TOHID study), registered in the Iranian Registry of Clinical Trials (www. IRCT.IR/Trial/5143) were recruited. The aim of previous study was to compare the effectiveness of long-term continuous MMI therapy with radioiodine (RAI) treatment in patients with GD; 239 patients with recurrence of hyperthyroidism after a conventional 1218 months of ATD treatment were divided into MMI and RAI groups. The diagnosis of Graves' hyperthyroidism was based on clinical findings of hyperthyroidism with or without Graves' orbitopathy, serum TSH $<0.4$ $\mathrm{mU} / \mathrm{L}$, free thyroxine (fT4) $>23 \mathrm{pmol} / \mathrm{L}$ and/or serum triiodothyronine (T3) > $200 \mathrm{ng} / \mathrm{dL}$, elevated TRAb levels $>1.75 \mathrm{IU} / \mathrm{L}$ and diffuse goiter without nodularity on technetium scintigraphy. Patients were prescribed 20$30 \mathrm{mg}$ MMI for the first month and titration method was used to maintain serum fT4 between 10 and 23 $\mathrm{pmol} / \mathrm{L}$ and serum TSH between 0.4-5.0 mU/L. Patients were visited monthly for the first 3 months of therapy and every six months thereafter by the principle investigator (F.A.). During each visit, complete history and a review of symptoms were documented and physical examination, in particular related to thyroid size and its function was performed. All possible adverse effects due to ATD therapy were ascertained. Cell blood count, serum levels of fT4, T3, TSH, alanine aminotransferase and aspartate aminotransferase were measured at baseline. At each visit, the dose of methimazole was adjusted to maintain serum $\mathrm{fT} 4$ and T3 concentration in the middle range of normal values and TSH in the reference range.

\section{Procedures}

For this study, all 59 patients who had been on LT-MMI treatment for $14.2 \pm 2.9$ years were recruited; the principle investigator (F.A.) explained about advantages and disadvantages of MMI withdrawal versus MMI continuation for additional years, doing his best not to influence on the patient choice. They were given the choice of either discontinuing MMI treatment or continue LTMMI therapy; 32 patients (54\%) decided to discontinue MMI and 27 (46\%) preferred continuous LT-MMI treatment (Fig. 1). All patients were followed every six months, as described above.

\section{Laboratory measurements}

Before 2005, serum fT4 and T3 were measured by radioimmunoassay kits from DiaMetra, Milan, Italy and serum TSH by immunoradiometric assay using kits from Izotop (Budapest, Hungary). Serum TRAb concentration was measured by enzme-linked immunoabsorbent assay (Bio Vendor Laboratory Medicine Inc., Czech Republic). Subsequently, all analyses were determined by electrochemiluminescence immunoassay (Roche Diagnostic $\mathrm{GmbH}$, Mannheim, Germany). Interassay and intraassay coefficients of variation of all tests were $<6.1 \%$ and $<9.1 \%$, respectively.

\section{Definitions}

Thyroid function status was defined as follows: Euthyroidism, TSH $0.4-5.0 \mathrm{mU} / \mathrm{L}$; hypothyroidism, $\mathrm{TSH}>5.0$ $\mathrm{mU} / \mathrm{L}$ and $\mathrm{fT} 4<9 \mathrm{pmol} / \mathrm{L}$; subclinical hypothyroidism, TSH $>5.0 \mathrm{mU} / \mathrm{L}$ and fT4 9-23 pmol/L; hyperthyroidism, $\mathrm{TSH}<0.4 \mathrm{mU} / \mathrm{L}$ and $\mathrm{fT} 4>23 \mathrm{pmol} / \mathrm{L}$ and/or T3 $>200$ $\mathrm{ng} / \mathrm{dL}$ and subclinical hyperthyroidism, TSH $<0.4 \mathrm{mU} / \mathrm{L}$ and fT4 9-23 pmol/L and T3 80-200 ng/dL.

\section{Outcomes}

The primary outcome of the study was sustained euthyroidism during the additional six years of follow-up. Key secondary outcomes were the occurrence of both clinical and subclinical hyper- and hypothyroidism during the length of study. Assessment of safety of MMI therapy was performed by observation of adverse events during the treatment.

\section{Statistical analysis}

Data are reported as mean $\pm \mathrm{SD}$ for continuous and number (percentages) for categorical variables. Significant differences were assessed by Student's t, MannWhitney, Chi-square and Fisher exact tests. Change of continuous variables during very long-term MMI treatment was analyzed using generalized estimating equation. Time to relapse of hyperthyroidism after MMI withdrawal was compared using Kaplan-Meier curves and log-rank test was used to compare survival curves. 


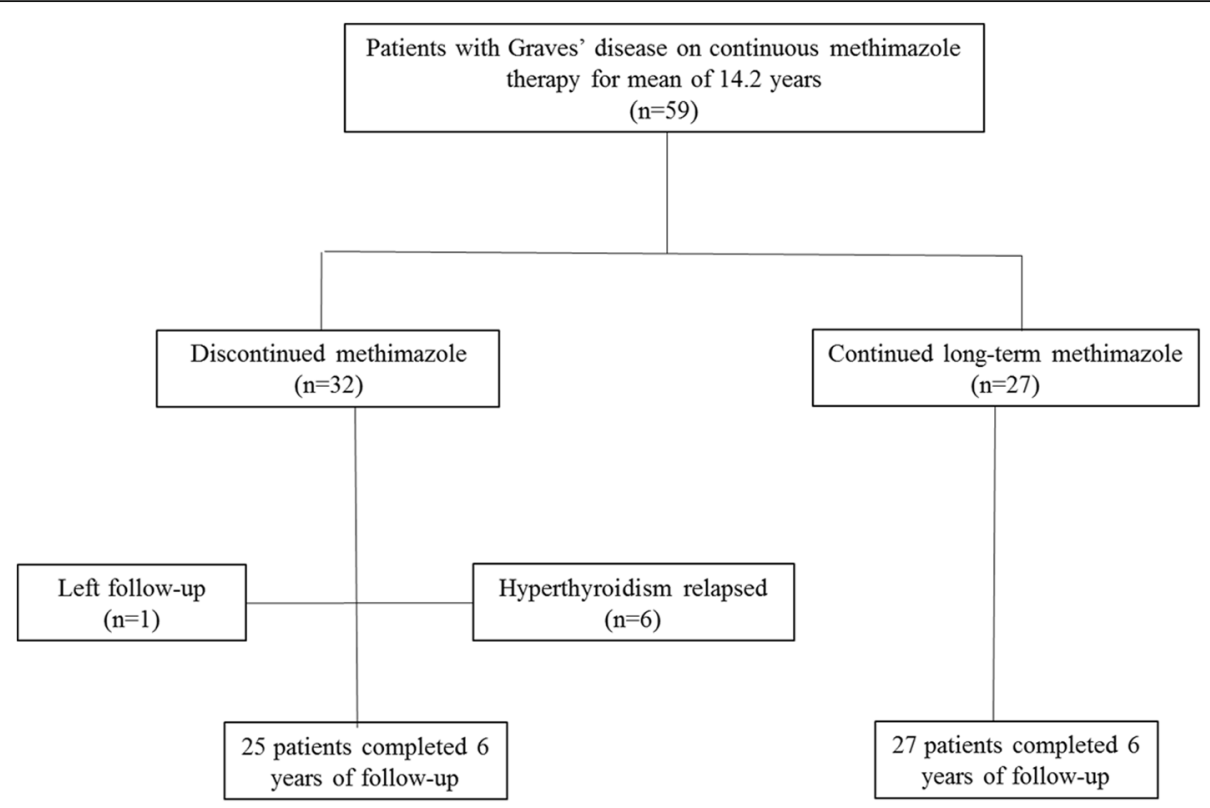

Fig. 1 Enrollment and follow-up of study patients

Statistical analysis was performed by SPSS 20 (SPSS Inc., Chicago, IL) and $p<0.05$ was considered significant.

\section{Results}

Baseline characteristics of two study groups are shown in Table 1. There were no significant differences in age, sex distribution, smoking status, goiter size and serum concentrations of fT4, T3, TSH and TRAb and daily MMI dosage at the time of this study entry between those who continued versus stopped MMI treatment. Nonetheless, patients who continued MMI therapy had received MMI for longer duration as compared to those who discontinued MMI (15.6 \pm 1.9 vs. $12.8 \pm 4.0$ years, respectively).

Table 1 Characteristics of two study groups at the start of the current study

\begin{tabular}{lll}
\hline Variables & Continued MMI $(\boldsymbol{n}=\mathbf{2 7})$ & Discontinued MMI $(\boldsymbol{n}=\mathbf{3 2})$ \\
\hline Age, year & $53.1 \pm 19.8$ & $49.7 \pm 12.4$ \\
Female, $n$ (\%) & $19(70)$ & $22(69)$ \\
High school diploma, $n(\%)$ & $11(41)$ & $12(38)$ \\
Goiter grade ${ }^{a}, n(\%)$ & & $10(31)$ \\
$\quad 0$ or 1 & $9(33)$ & $22(69)$ \\
2 & $18(67)$ & $5(16)$ \\
Current smoking, $n(\%)$ & $4(15)$ & $5(16)$ \\
Ophthalmopathy, $n(\%)$ & $4(15)$ & $15.8 \pm 2.6$ \\
fT4, pmol/L & $16.1 \pm 2.4$ & $132 \pm 26$ \\
T3, ng/dL & $125 \pm 21$ & $2.9 \pm 1.2$ \\
TSH, mIU/L & $3.0 \pm 0.6$ & $1.1 \pm 0.7$ \\
TRAb, IU/L ${ }^{b}$ & $1.3 \pm 0.6$ & $3.8 \pm 1.2$ \\
MMI dose, mg/day & $3.4 \pm 1.1$ & $12.8 \pm 4.0$ \\
Duration of MMl therapy, years ${ }^{\ddagger}$ & $15.6 \pm 1.9$ & $9(28)$
\end{tabular}

Abbreviations: MMI methimazole; fT4 free thyroxine; T3 triiodothyronine; TSH thyrotropin, TRAb TSH receptor antibody

${ }^{\mathrm{a}}$ Goiter size: Grade 0, thyroid is not palpable or visible; grade I, thyroid is easily palpable but not visible; grade 2, thyroid easily visible with the head in the normal position

${ }^{\mathrm{b}}$ Serum TRAb concentration was below $2.3 \mathrm{IU} / \mathrm{L}$ in all patients

${ }^{c}$ Comorbidities included documented diabetes, hypertension, or dyslipidemia

${ }^{\ddagger} P$-value $<0.001$ 


\section{Continued MMI group}

At the start of the current study, 27 patients including 19 females and 8 males of this group were $53.1 \pm 19.8$ years old and have already been on $15.6 \pm 1.9$ years of LT-MMI therapy. Figure 2 shows serum concentrations of TSH and MMI dosages used to maintain euthyroidism during 24 years of continuous LT-MMI treatment. After 3 months of MMI treatment, serum TSH increased to normal range in $12(44 \%)$ of patients. By 4 years after LT-MMI, only 4 (15\%) had at least one suppressed TSH during the follow-up. Seven years after the start of LTMMI, no suppressed TSH was observed and TSH remained stable and in normal range in all patients up to 24 years following MMI treatment $(p=0.32)$. Serum fT4 decreased from a mean of $39.1 \pm 9.2 \mathrm{pmol} / \mathrm{L}$ at the baseline to $16.1 \pm 25,16.3 \pm 2.4$ and $16.2 \pm 2.2 \mathrm{pmol} / \mathrm{L}$ at 15,20 and 24 years after LT-MMI treatment; the decreasing trend of fT4 concentration from the first to the 24 th year of treatment was significant $(p<0.001)$. Mean serum T3 concentration decreased from $401 \pm 126 \mathrm{ng} / \mathrm{dL}$ to $125 \pm 18,123 \pm 17$ and $124 \pm 17 \mathrm{ng} / \mathrm{dL}$ at 15,20 and 24 years of treatment; the decreasing trend of T3 from the first to the 24th year of treatment was also significant $(p<0.001)$ (Table 2). Mean serum concentration of TRAb was $15 \pm 8 \mathrm{IU} / \mathrm{ml}$ at baseline and decreased to 1.2 , 1.1, 1.0 and $0.9 \mathrm{IU} / \mathrm{ml}$ after 2, 8, 16 and 24 year of LTMMI therapy ( $p<0.001$, Fig. 2). After 6 years of continuous MMI therapy, none of the patients had TRAb levels above $1.7 \mathrm{IU} / \mathrm{ml}$.
Mean dose of MMI was $9.8 \pm 1.0 \mathrm{mg}$ daily after three months of therapy and decreased to $5.4 \pm 1.6 \mathrm{mg}$ per day by the end of the first year of MMI treatment. Daily doses of MMI to maintain euthyroidism were gradually lowered to $\leq 5 \mathrm{mg}$ by 10 years after the start of study in all patients. Mean daily dose of MMI decreased to $2.8 \pm$ $1.7 \mathrm{mg}$ daily after 24 years of LT-MMI treatment (Fig. 2); 5 of 11 patients required $\leq 2.5 \mathrm{mg}$ daily MMI to remain euthyroid. None of the subjects showed recurrence on therapy. Six patients developed minor skin reactions in the first few months of therapy; adverse reactions such as agranulocytosis and liver dysfunction were not observed. Thereafter, no adverse reactions related to MMI occurred during 24 years of follow-up.

\section{Discontinued MMI group}

Twenty-two females and 10 males, aged $49.7 \pm 12.4$ years who were on LT-MMI for $12.8 \pm 4.0$ years, decided to discontinue MMI treatment. Trends of changes in serum concentrations of fT4, T3, TSH, TRAb and MMI dosage during 12.8 years of MMI treatment was not different from patients who decided to continue MMI treatment. Of these 32 patients, one left follow-up; overt hyperthyroidism relapsed in six patients during 6 years of followup. Two, two, one and one patients recurred at $6,12,32$ and 50 months after discontinuation of MMI treatment. Other 25 (78\%) patients in this group had normal serum concentrations of fT4, T3 and TSH and serum TRAb $<1.7 \mathrm{IU} / \mathrm{ml}$ during 6 additional years of follow-up.

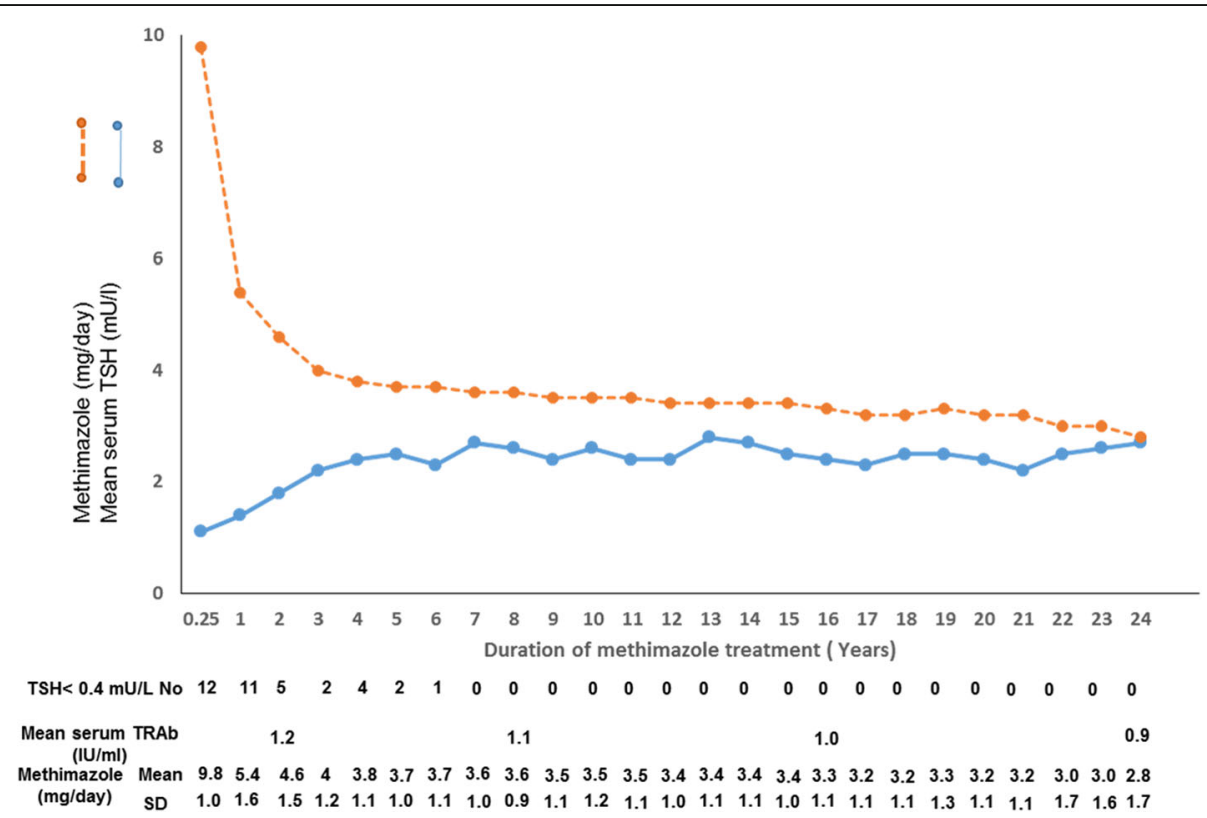

Fig. 2 Serum concentrations of TSH and TSH receptor antibody (TRAb) and mean daily doses of methimazole during 24 years of continuous methimazole treatment. All 27 patients continued therapy for at least 15 years, 16 patients until 20 years and 11 patients until 24 years. Daily doses of methimazole to maintain euthyroidism decreased to mean of $3.4 \pm 1.0$ and $2.8 \pm 1.7 \mathrm{mg}$ daily, by 15 and 24 years of therapy; suppressed serum TSH was not seen in any patient after 7 years of treatment. Serum TRAb was normal in all patients during methimazole treatment 
Table 2 Serum concentrations of thyroid hormones, TSH and TRAb in Graves' patients during 24 years of continuous long-term MMI treatment

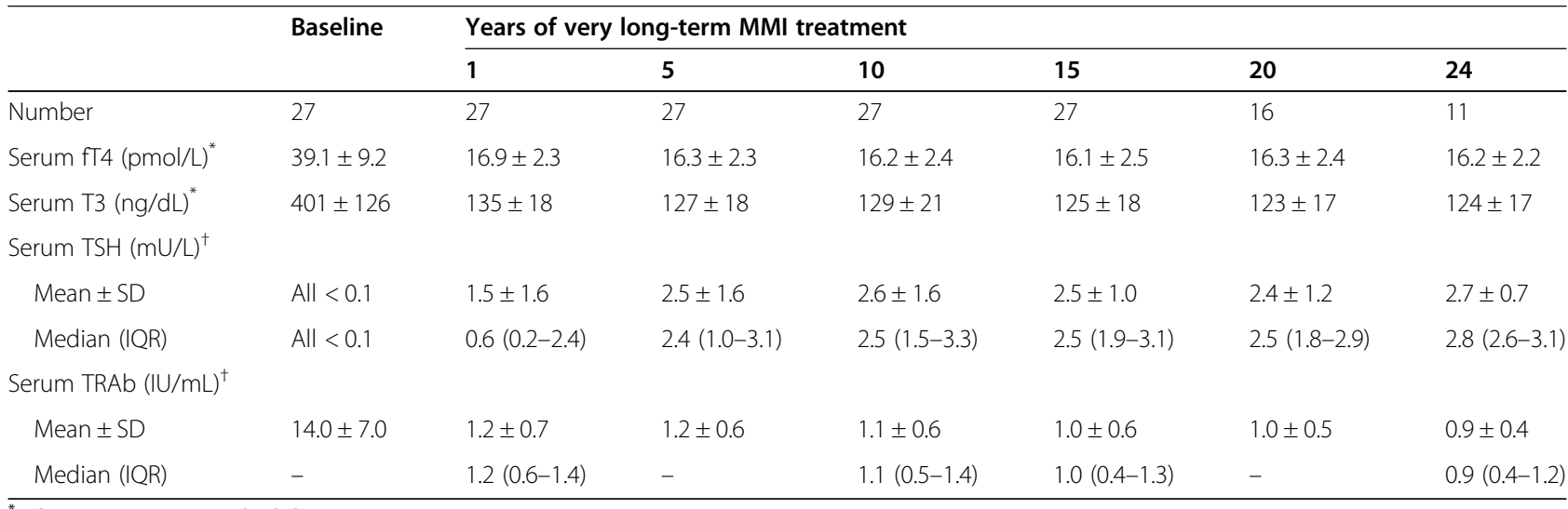

"Values are mean \pm standard deviation

${ }^{\dagger}$ Normally distributed values. Serum concentrations of TSH and TRAb were in normal range after 6 years of treatment

fT4 free thyroxine, T3 triiodothyronine, TSH thyrotropin, TRAb TSH receptor antibody, MMI methimazole

Figure 3 shows Kaplan-Meier curve for relapse of hyperthyroidism in patients who continued and those who discontinued MMI after 6 years of follow-up. There was no relapse in the first group and 19\% relapse in the second group (log $\operatorname{rank} p=0.019)$.

\section{Discussion}

The present study demonstrates continuous decline in serum fT4 and T3 concentrations and rise in serum TSH during 24 years of MMI treatment accompanied by continuous normalization of serum TRAb and gradual decrease in daily doses of MMI to maintain euthyroid state. We have not found any episode of exacerbation of hyperthyroidism during 24 years of follow-up in patients treated with continuous LT-MMI treatment. In addition, no adverse events occurred after the first year up to 24 years of continuous MMI treatment; findings in agreement with a recent systematic review on safety of longterm ATD treatment [15].

Several studies have reported that in patients who experience relapse of hyperthyroidism after 12-18 months of ATD therapy, remission may be attained by additional 5 to 10 years of treatment $[8,11,14]$ Therefore, some patients may prefer continuous lifelong MMI therapy for management of Graves' hyperthyroidism. In the present study, majority of patients who discontinued treatment after mean 12.8 years of continuous MMI stayed euthyroid during 6 years of follow-up; only $19 \%$ experienced relapse of hyperthyroidism. Results are similar to other studies reporting increased remission rates in Graves'

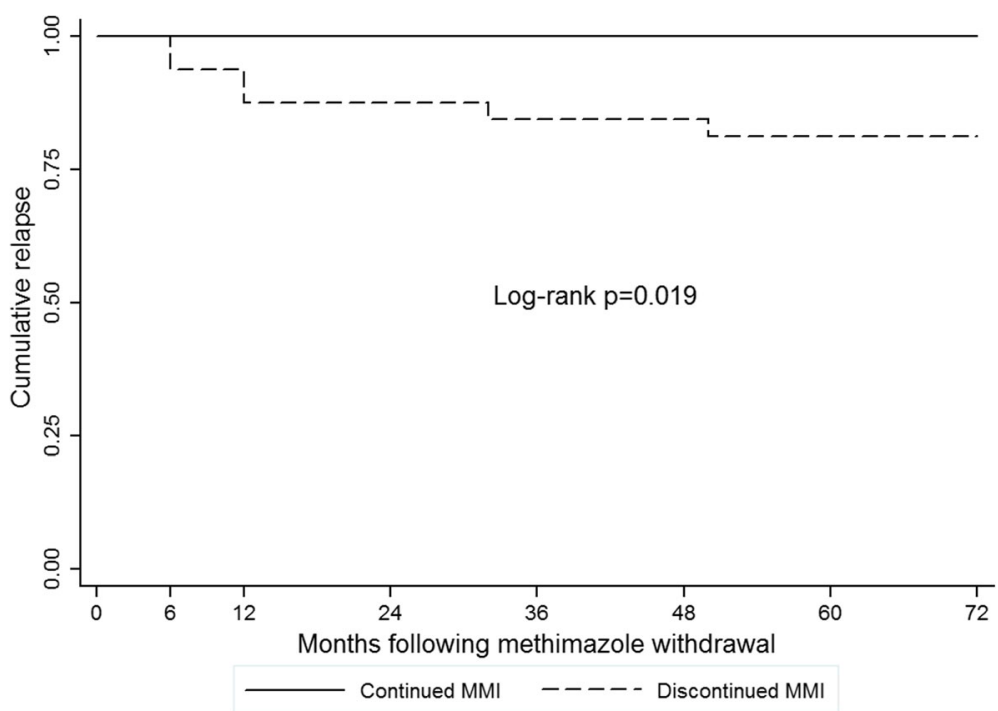

Fig. 3 Kaplan-Meier curve for relapse of hyperthyroidism in patients with Graves' disease after long-term methimazole (MMI) treatment. No recurrence was observed in patients who continued MMl; hyperthyroidism relapsed in 19\% of those who discontinued MMI therapy 
hyperthyroidism after long-term MMI therapy, compared to the conventional 12-18 month ATD therapy [11]. A proposed justification for the observed results of LT-MMI therapy is related to immunomodulatory properties of MMI, an effect which is not yet fully understood [16].

The 2016 American Thyroid Association guidelines recommend RAI or thyroidectomy as the therapeutic choices in the setting of hyperthyroidism after the conventional 12-18 months of ATD therapy; continuous low dose MMI has been suggested in patients with persistently high TRAb concentrations [4]. Safety of LTATD treatment has been shown in clinical studies [15]. Likewise, based on the findings of a recently published trial, LT-ATD treatment of $\geq 5$ years induces cure of disease in $86 \%$ of patients with GD after ATD discontinuation [14]. In a large cohort of GD patients treated by ATD from Japan, Okamura, et al. showed that serum TRAb level may become normal following the conventional ATD treatment but it will fluctuate and remission of GD occurs after the median 6.2 years of ATD therapy [17]. These findings point to the importance of LT-ATD treatment to ensure higher probability of remission.

The beneficial effect of LT-ATD therapy has been documented in patients with Graves' orbitopathy [9] and those with relapse of hyperthyroidism following conventional 12-18 months ATD treatment $[6,8]$. It has also been recommended in patients with high serum TRAb concentration at the end of 18 months course of ATD therapy [4]. Our experience in the present study shows that even in those with continuous positive TRAb, LTMMI treatment causes gradual decrease of serum TRAb concentrations and remission of hyperthyroidism. Previous studies have also shown more stable euthyroidism and comparable or better cost-benefit when compared to RAI treatment [6]. Considering recent findings that effective control of hyperthyroidism improves cardiovascular outcomes [18], a stable euthyroid state during continuous MMI treatment highlights a potential advantage of this mode of therapy.

Strengths of this study are the longest follow-up of patients with continuous MMI therapy and demonstration of the point of normalization of TSH in all treated patients. In addition, findings emphasize the fact that many patients require $<2.5 \mathrm{mg}$ MMI daily to remain euthyroid and there is paucity of adverse events on low dose LTMMI treatment. Following limitations are noteworthy; first, the study arm was selected by each patient choice; therefore, study enrollment was not randomized and possibilities of biases may exist which can affect the results. Second, with regards to the proposed relationships between iodine intake and efficacy of ATDs, although still unresolved and contradictory [19], our findings in an iodine-sufficient population may not be generalizable to other regions. Third, those who continued very LTMMI treatment were already 2.8 years more on MMI than patients who discontinued medication.

In conclusion, long-term low dose MMI treatment may be prescribed effectively, even throughout the patients' life for those with Graves' hyperthyroidism who do not desire ablation treatment. Low cost, safe and effective drugs are prescribed as lifelong therapy for some specific diseases, such as epilepsy, inflammatory bowel disease and hypothyroidism and MMI may be added to the list of lifelong drugs for control of Graves' hyperthyroidism. During long-term MMI therapy in women of reproductive age, special attention should be made to discontinue MMI or change to propylthiouracil in those planning for pregnancy [20]. It is noteworthy that final decision to select mode of treatment in GD is according to physicians and patients decisions and some may prefer definitive therapy of hyperthyroidism by ablation over long-term treatment. In addition, the findings of the present article are from a single-center study by investigators with expertise in low dose MMI therapy. Further very long-term ATD treatment studies from other clinical centers with more sophisticated designs in order to minimize biases will shed more light on the efficacy of this mode of therapy in GD and perhaps other causes of hyperthyroidism.

\section{Acknowledgements \\ We appreciate Ms. Leila Cheraghi for her kind contribution to statistical analyses.}

\section{Authors' contributions}

F.A.: Study design, data collection, analyses and interpretation, and writing of the manuscript draft. A.A.: Data collection and interpretation, and writing of the final manuscript. H.A.: Data interpretation and writing of the final manuscript. The authors read and approved the final manuscript.

Funding

There is no funding support.

Availability of data and materials

The datasets generated and/or analysed during the current study are not publicly available due to repository at a private clinic but are available from the corresponding author on reasonable request.

\section{Ethics approval and consent to participate}

The study protocol was approved by the ethics committee of the Research Institute for Endocrine Sciences of Shahid Beheshti University of Medical Sciences, Tehran, Iran.

All study subjects provided a written informed consent.

Consent for publcation

Not Applicable.

Competing interests

All authors have no conflicts of interest to declare. 
Received: 7 July 2020 Accepted: 18 December 2020

Published online: 14 January 2021

\section{References}

1. Bartalena L, Burch H, Burman K, Kahaly G. A 2013 European survey of clinical practice patterns in the management of Graves' disease. Clin Endocrinol. 2016;84(1):115-20.

2. Brito JP, Schilz S, Singh Ospina N, et al. Antithyroid drugs - the most common treatment for Graves' disease in the United States: a nationwide population-based study. Thyroid. 2016;26(8):1144-5.

3. Smith TJ, Hegedüs L. Graves' disease. N Engl J Med. 2016;375(16):1552-65.

4. Ross DS, Burch HB, Cooper DS, et al. 2016 American Thyroid Association guidelines for diagnosis and management of hyperthyroidism and other causes of thyrotoxicosis. Thyroid. 2016;26(10):1343-421.

5. Bandai S, Okamura K, Fujikawa M, Sato K, Ikenoue H, Kitazono T. The longterm follow-up of patients with thionamide-treated graves' hyperthyroidism. Endocr J. 2019;66(6):535-45.

6. Azizi F, Ataie L, Hedayati M, Mehrabi Y, Sheikholeslami F. Effect of long-term continuous methimazole treatment of hyperthyroidism: comparison with radioiodine. Eur J Endocrinol. 2005:152(5):695-701.

7. Azizi F, Yousefi V, Sheikholeslami F, Tohidi M. Long-term continuous methimazole or radioiodine treatment for hyperthyroidism. Arch Iran Med. 2012;15(8):477

8. Villagelin D, Romaldini $\mathrm{JH}$, Santos RB, Milkos AB, Ward LS. Outcomes in relapsed Graves' disease patients following radioiodine or prolonged low dose of methimazole treatment. Thyroid. 2015;25(12):1282-90.

9. Elbers L, Mourits M, Wiersinga W. Outcome of very long-term treatment with antithyroid drugs in Graves' hyperthyroidism associated with Graves' orbitopathy. Thyroid. 2011;21(3):279-83.

10. Chen DY, Jing J, Schneider PF, Chen TH. Comparison of the long-term efficacy of low dose 1311 versus antithyroid drugs in the treatment of hyperthyroidism. Nucl Med Commun. 2009;30(2):160-8.

11. Azizi F, Malboosbaf R. Long-term antithyroid drug treatment: a systematic review and meta-analysis. Thyroid. 2017;27(10):1223-31.

12. Cooper DS. Long-term Antithyroid drug treatment of patients with graves disease. Clin Thyroidol. 2019;31(6):230-3

13. Kahaly GJ, Bartalena L, Hegedüs L, Leenhardt L, Poppe K, Pearce SH. 2018 European thyroid association guideline for the management of graves hyperthyroidism. Eur Thyroid Journal. 2018;7(4):167-86.

14. Azizi F, Amouzegar $A$, Tohidi $M$, et al. Increased remission rates after longterm methimazole therapy in patients with Graves' disease: results of a randomized clinical trial. Thyroid. 2019;29(9):1192-200.

15. Azizi F, Malboosbaf R. Safety of long-term antithyroid drug treatment? A systematic review. J Endocrinol Investig. 2019:1-11.

16. Burch HB, Cooper DS. Anniversary review: antithyroid drug therapy: 70 years later. Eur J Endocrinol. 2018:179(5):R261-R74.

17. Okamura K, Bandai S, Fujikawa M, Sato K, Ikenoue H, et al. Long-Term Antithyroid Drug Treatment: Trends in Serum TSH and TSH Receptor Antibody Changes in Patients with Graves' Disease. Int J Endocrinol Metab. 2020;18(Suppl):e101139. https://doi.org/10.5812/ijem.101139.

18. Okosieme OE, Taylor PN, Evans C, et al. Primary therapy of Graves' disease and cardiovascular morbidity and mortality: a linked-record cohort study. Lancet Diab Endocrinol. 2019;7(4):278-87.

19. Pearce EN. A low-iodine diet during Methimazole treatment worsens graves' disease outcomes. Clin Thyroidol. 2018;30(2):66-8.

20. Alexander EK, Pearce EN, Brent GA, et al. 2017 guidelines of the American Thyroid Association for the diagnosis and management of thyroid disease during pregnancy and the postpartum. Thyroid. 2017;27(3):315-89.

\section{Publisher's Note}

springer Nature remains neutral with regard to jurisdictional claims in published maps and institutional affiliations.

Ready to submit your research? Choose BMC and benefit from:

- fast, convenient online submission

- thorough peer review by experienced researchers in your field

- rapid publication on acceptance

- support for research data, including large and complex data types

- gold Open Access which fosters wider collaboration and increased citations

- maximum visibility for your research: over $100 \mathrm{M}$ website views per year

At $\mathrm{BMC}$, research is always in progress.

Learn more biomedcentral.com/submissions 